\title{
Relation between fluid overload and mortality in children with septic shock
}

\author{
Horacio Márquez-González, M.D. ${ }^{a, b}$, Luis Casanova-Bracamontes, M.D. ${ }^{a}$, \\ C. Mireya Muñoz-Ramirez, M.D. ${ }^{a, c}$, Leoncio Peregrino-Bejarano, M.D. ${ }^{a}$, \\ Bárbara Bolaños-Téllez, M.D. ${ }^{a}$ and Lucelli Yáñez-Gutiérrez, M.D. ${ }^{d}$
}

\begin{abstract}
Septic shock is one of the main causes of mortality Fluid replacement stands out as the treatment of choice to reduce mortality.

Objective. To determine the relation between the percentage of fluid overload $(\% \mathrm{FO})$ and mortality in children with septic shock.

Methods. Cohortstudy in patients aged 1-17 years with septic shock, after fluid replacement with central venous pressure $\geq 5 \mathrm{mmHg}$, invasive monitoring, and complete recording of $\% \mathrm{FO}$ up to $96 \mathrm{~h}$. Follow-up and outcome measures were recorded up to day 28. The following outcome measures of septic shock were recorded: refractory shock, cause of acute kidney injury, anemia, malnutrition, time to antibioticinitiation, oncotic pressure, and severity score.

Statistical analysis. The hazard ratio (HR) was estimated and three Cox proportional hazard models were developed.

Results. The population included 263 patients; their average age was $8 \pm 3$ years. Mortality was $33 \%$. A $\% \mathrm{FO} \geq 10.1 \%$ accumulated at 96 $\mathrm{h}$ was the only associated outcome measure; the HR (95\% confidence interval) was adjusted for hemodynamic profile, $\mathrm{HR}=2.6$ (1.9$5.6)$; refractory shock, $\mathrm{HR}=2.5$ (1.6-5.6); and malnutrition, $\mathrm{HR}=8.3$ (3.5-14).

Conclusions. A $\% \mathrm{FO}>10.1 \%$ was related to a higher mortality at 28 days of adjustment for hemodynamic profile, refractory shock, and nutritional status.

Key words: septic shock, childhood mortality, electrolyte balance.
\end{abstract}

http:/ / dx.doi.org/10.5546/ aap.2019.eng.105

To cite: Márquez-González H, Casanova-Bracamontes L, Muñoz-Ramírez CM, Peregrino-Bejarano L, et al. Relation between fluid overload and mortality in children with septic shock. Arch Argent Pediatr 2019;117(2):105-113.

\section{INTRODUCTION}

It is estimated that 7.5 million pediatric patients die every year as a result of sepsis. Mortality due to septic shock is approximately $15 \%{ }^{1}$

Septic shock generates a status of generalized vasodilation due to pro-inflammatory cytokine release, which reduces the volume of the intravascular space; therefore, the administration of intravenous solutions is the baseline treatment. ${ }^{2}$ A prolonged administration of fluids to the venous compartment causes congestion that harms the endothelial glycocalyx and favors leaking to the interstitial space, thus conditioning secondary hypoperfusion and organ injury. ${ }^{3}$

The Acute Dialysis Quality Initiative (ADQUI) was part of a task force that divided fluid therapy for critically ill patients into four phases, during which fluids should be progressively reduced. The phases were classified as rescue, optimization, stabilization, and deescalation. ${ }^{4}$

In the adult population, a positive fluid balance has been described to lead to a higher risk of death, acute kidney injury (AKI), and prolonged mechanical ventilation requirement. In pediatrics, study results have been heterogeneous due to the diverse eligibility criteria and prognostic outcome measures included; for this reason, the evidence on mortality is ambiguous, which warrants the conduct of cohort studies. ${ }^{5}$ Adherence to the tiered resuscitation strategy for septic shock proposed by the Surviving Sepsis Campaign Guidelines has demonstrated that the time of fluid administration initiation is associated with a lower mortality, but not with the administered volume. ${ }^{6}$

The objective of this study was to determine the relation between the percentage of fluid overload ( $\% \mathrm{FO})$ and mortality adjusted based on confounding outcome measures in patients with septic shock.
Received: $10-30-2017$ Accepted: 10-30-2018 


\section{MATERIAL AND METHODS}

A prognostic study was done in a prospective cohort at a children's hospital, between January 2011 and December 2016. The study was approved by the Local Research Ethics Committee and required the mandatory signature of the informed consent by the parents. This cohort was made up of patients aged 1-17 years with septic shock (sepsis with blood pressure $\leq 2$ standard deviations adjusted to sex, age, and height standardized tables, ${ }^{7}$ and three or more of the following: tachycardia $\geq 180$ beats per minute in infants or $\geq 160$ beats per minute in preschool children, decreased pulse, urine output $\leq 1 \mathrm{~mL} / \mathrm{kg} / \mathrm{h}$ in children with a weight $<30 \mathrm{~kg}$ or $\leq 0.5 \mathrm{~mL} / \mathrm{kg} / \mathrm{h}$ in those with a weight $\geq 30 \mathrm{~kg}$, respiratory rate higher than the $90^{\text {th }}$ percentile for age or assisted mechanical ventilation requirement). ${ }^{8}$

Inclusion criteria were male and female patients with septic shock receiving early fluid therapy (up to 3 loads of $20 \mathrm{~mL} / \mathrm{kg}$ in the first hour), central venous pressure (CVP) between 8 and $16 \mathrm{mmHg}^{9}$, and blood sample collection in the first hour after fluid replacement (arterial and central venous blood gas, blood culture, and urine culture), anthropometric measurements (weight and height) according to Zerfas standardized technique ${ }^{10}$ (calibrated scale, stadiometer, and infantometer) and admission to the pediatric intensive care unit (PICU) on the first day. The following patients were excluded: children with comorbidities, such as congenital heart disease, pediatric cerebral palsy, amputation, severe pulmonary disease (interstitial lung disease or severe pulmonary hypertension), stage 3 or above chronic kidney disease, history of septic shock in the past 6 months, and those whose parents refused to complete the informed consent. The following were eliminated: patients who died for reasons other than septic shock, those lost to follow-up due to transfer to a different unit, and those whose electrolyte balance sheet was incomplete.

Time zero for the cohort was defined as the time of fluid replacement completion; outcomes were recoded up to day 28 . The following outcome measures were assessed:

1. Hemodynamic profile of septic shock: ${ }^{8}$ the following calculations were made based on arterial and central venous blood gas results.

- Arterial oxygen content $\left(\mathrm{CaO}_{2}\right)$ and venous oxygen content $\left(\mathrm{CvO}_{2}\right)$ were estimated by replacing their value in the following formula for each product: hemoglobin $(\mathrm{g} /$ dL) $\times 1.34 \times$ (oxygen saturation [\%]/100) + ( $0.0031 \times$ oxygen pressure in $\mathrm{mmHg}$ ).

- Arteriovenous oxygen difference $\left(\mathrm{a}-\mathrm{vO}_{2}\right.$ diff $)=\mathrm{CaO}_{2}-\mathrm{CvO}_{2}$.

- Oxygen consumption $\left(\mathrm{VO}_{2}\right)$ in $\mathrm{mL} / \mathrm{min} /$ $\mathrm{m}_{2}=1.39 \mathrm{x}$ weight in $\mathrm{kg}+0.84 \mathrm{x}$ height in $\mathrm{cm}-35.7 .12$

- Cardiac index (CI) in $\mathrm{L} / \mathrm{min}=\mathrm{VO}_{2} /(10 \mathrm{x}$ a- $\mathrm{vO}_{2}$ diff) divided by body surface area (BSA).

- Systemic vascular resistance index (SVRI) in dynes $=(\mathrm{CVP}$ in $\mathrm{mmHg}-$ mean blood pressure $) * 80 / \mathrm{CI}$.

It was classified into hyperdynamic profile $(\mathrm{CI} \geq 5.5 \mathrm{~L} / \mathrm{min}, \mathrm{SVRI} \leq 800$ dynes and a- $\mathrm{vO}_{2}$ diff $\left.\leq 3\right)$ and hypodynamic profile $\left(\mathrm{CI}<3.3 \mathrm{~L} / \mathrm{min} ; \mathrm{SVRI} \leq 800\right.$ dynes, a- $\mathrm{vO}_{2}$ diff $\geq 5$, and central venous oxygen saturation below $70 \%)$. ${ }^{8}$ Septic shock was defined as refractory to inotropes and vasopressors if there was a persistent catecholamine requirement (epinephrine $>0.1 \mathrm{mcg} / \mathrm{kg} /$ min, norepinephrine $>0.1 \mathrm{mcg} / \mathrm{kg} / \mathrm{min}$ or dopamine $>10 \mathrm{mcg} / \mathrm{kg} / \mathrm{min}$ ) for more than 24 h. $^{13}$

2. \%FO: fluid in and fluid out were collected from the daily electrolyte balance sheet at $24 \mathrm{~h}$ intervals up to day 4 . The $\% \mathrm{FO}$ accumulated per day was estimated using the formula proposed by Sutherland $(\% \mathrm{FO}=$ fluid in [L] - fluid out [L]/ weight in $\mathrm{kg} \times 100),{ }^{14}$ and stratified into three categories: 0-5\%, 5.1-10\%, and $\geq 10.1 \%$.

3. Determinants of septic shock: these were grouped into 2 categories, depending on prior comorbidities and the patient's risk factors: 1) fever and neutropenia, which included patients with a baseline blood disease and cancer diagnosis with fever and neutrophils $<$ 500 cells $/ \mathrm{mm}^{3}$ upon admission during the first 7-10 days after chemotherapy and 2) patients with microorganisms isolated in blood cultures. The scale used to stratify severity at the PICU was the Pediatric Index of Mortality 2 (PIM2) ${ }^{15}$ for the first $24 \mathrm{~h}$ corresponding to the first hour of admission to the hospital.

4. The development of acute kidney injury (injury, damage, failure) during the followup period based on diagnostic criteria of the Guidelines for Acute Kidney Injury. ${ }^{16}$

5. Quality and number of intravenous solutions used for fluid replacement and characteristics of inotropes and vasopressors used. 
6. Other outcome measures were recorded too, including the presence of malnutrition, defined by less than 2 standard deviations of weight for height according to the growth charts published by the World Health Organization (WHO) in 2006; ${ }^{17}$ serum lactate level after fluid replacement, which was considered altered if $\geq 4 \mathrm{mmol} / \mathrm{L}$; presence of anemia, defined as hemoglobin level $<9 \mathrm{~g} /$ $\mathrm{dL}$; and oncotic pressure [(serum albumin $\mathrm{x}$ $5.54)+($ serum globulin $\times 1,43)]$, which was considered abnormal if $<19.4 \mathrm{mmHg}$. $^{18}$

To collect information, the treating physician (independent from the statistical analysis) completed the daily sheet. Recorded weight and height corresponded to the values recorded upon admission in the patient's latest hospitalization (for those with admission for less than 3 days; for those with a longer length of stay, the latest recorded values before septic shock were used).

Statistical analysis: Qualitative outcome measures were stated as absolute frequency and percentage. Quantitative outcome measures were described according to their distribution, using measures of central tendency (mean, median) and dispersion (standard deviation or range).

The bivariate analysis compared survivors and deceased patients using the $\chi^{2}$ test for qualitative outcome measures and the t test or MannWhitney U test for quantitative ones. Statistically significant outcome measures were dichotomized and the absolute risk was estimated based on the hazard ratio (HR). To develop the prognostic models, the Cochran-Mantel-Haenszel statistics were used in the first place to identify the main confounding outcome measures. Those with a $p<0.1$ or clinically relevant were then introduced to develop Cox proportional hazard models. Survival was analyzed using Kaplan-Meier for the $\%$ FO. A value of $p<0.05$ was considered statistically significant. The statistical package SPSS (IBM) for Mac, version 20, was used.

\section{RESULTS}

The final sample was made up of 242 patients (Figure 1), whose average age was $8 \pm 3$ years; of these, $144(59.5 \%)$ were girls. Among the total sample, $88(36.4 \%)$ developed some degree of acute kidney injury. A total of 126 patients (52\%) had a diagnosis of blood disease and cancer; 102 of them had fever and neutropenia. Eighty deaths were recorded $(33 \%)$.

Microbiological isolation was confirmed in 92 cases: 24 Staphyloccocus (18 Staphylococcus aureusand 6 coagulase-negative Staphylococcus), 23 Pseudomonas aeruginosa, 17 Escherichia coli, 15 Klebsiella spp., 5 Acinetobacterbaumannii, and 8 Candida spp.

The following outcome measures were observed when comparing the groups of live and dead patients (Table 1): male sex, hypodynamic profile of septic shock, refractory shock, mechanical ventilation in the first $24 \mathrm{~h}$, and malnutrition.

Among the studied quantitative outcome measures, differences between the live and dead groups were observed in the PIM2 score ( $7 \pm 2$ versus $11 \pm 2$ ), the time between septic shock diagnosis and antibiotic initiation (42 \pm $17 \mathrm{~min}$ versus $61 \pm 18 \mathrm{~min}$ ), oncotic pressure $(24 \pm 1.2 \mathrm{mmHg}$ versus $21 \pm 1.4 \mathrm{mmHg})$, and serum lactate $(3.2 \pm 1.7 \mathrm{mmol} / \mathrm{L}$ versus $4.3 \pm 1.5 \mathrm{mmol} / \mathrm{L}$ ).

The average $\% \mathrm{FO}$ accumulated by hour of progress was higher in the dead patient group as of $48 \mathrm{~h}$ (Table 1). Figure 2 shows the differences between both groups.

\section{Survival analysis}

To determine the accumulated $\% \mathrm{FO}$ for inclusion in the survival analysis, data were stratified by hour $(24,48,72$, and $96 \mathrm{~h})$ and into 4 categories (negative $\% \mathrm{FO}, 0-5 \%, 5.1-10 \%$, and $\geq 10.1 \%)$. The only statistically significant risk corresponded to a $\% \mathrm{FO} \geq 10.1 \%$ at $96 \mathrm{~h}$ (Table 2 ).

To avoid colinearity, 3 prognostic models were developed (Table 3). Model 1 was analyzed including only one septic shock outcome measure: baseline hemodynamic profile (hyperdynamic or hypodynamic). In model 2 , this was replaced by refractory shock (presence or absence). A third model was developed exclusively for patients with malnutrition (of any extent). The 3 models showed that a $\% \mathrm{FO}>10.1 \%$ was a risk factor for mortality. Figure 3 shows the Kaplan-Meier survival curve.

\section{DISCUSSION}

In this study, the mortality of patients with septic shock was $33 \%$. Other published studies with similar objectives reported different frequencies due to eligibility criteria; however, if only subjects with septic shock was the eligibility criterion, as in the cohort studied by Chen et al., the relation with mortality was practically the same $(30 \%) .{ }^{19}$

The bivariate analysis showed that the dead patient group had a higher average $\% \mathrm{FO}$ 
accumulated over the first 4 days. When the analysis was stratified by $\% \mathrm{FO}$ range, the only one related to a significant risk was that corresponding to $96 \mathrm{~h}$.

In the adult population, Garzotto et al., conducted a multicenter study that reported a $4 \%$ increase in the probability of death for each percentage point of increase in the $\% \mathrm{FO}^{20}$

In the pediatric population, the accumulated $\% \mathrm{FO}$ was associated with an increase in the number of days of assisted mechanical ventilation. However, when death was the studied outcome measure, some authors like Abulebda ${ }^{21}$ and Willson ${ }^{22}$ did not establish such association; whereas others did, such as Li and Chen ${ }^{19}$ and Bhaskar ${ }^{23}$ (who used eligibility criteria similar to those of this study).

In addition, in this study, we decided to include the assessment of the hemodynamic profile according to the CI estimation in a formula based on the Fick method, supported by previous studies done in animal and nonpediatric populations with an $r$ value of 0.61 0.8824 with the thermodilution technique and 0.88 with Doppler ultrasound. ${ }^{25}$

As a strategy to establish the prognostic value of the $\% \mathrm{FO}$ over other confounding outcome measures, 3 prognostic models were designed.

FIGURE 1. Flow chart of eligibility of patients with septic shock included in the cohort

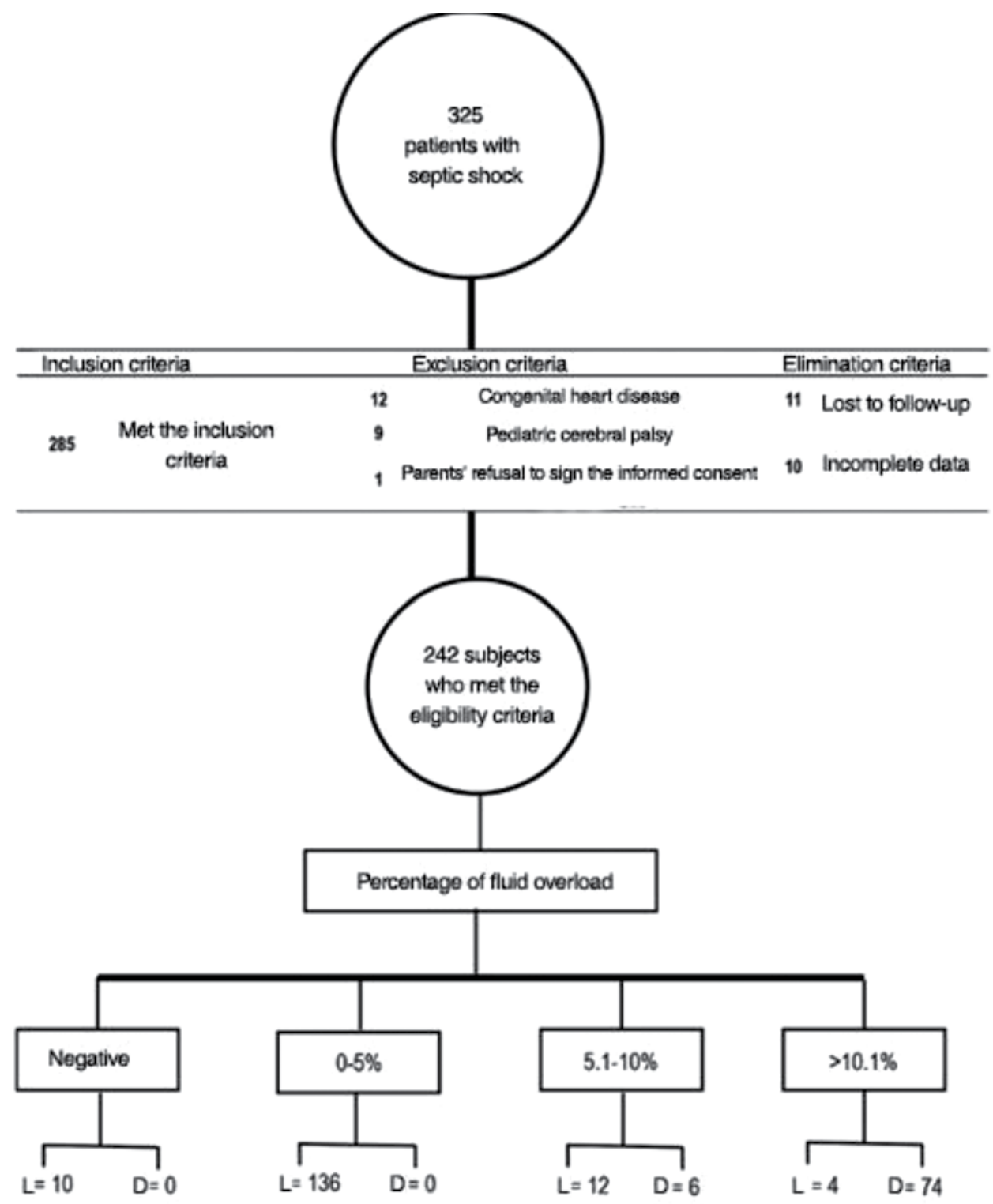

$\mathrm{L}=$ live, $\mathrm{D}=$ dead 
TABLE 1. General characteristics of the population of patients with septic shock and differences between live and dead patients

\begin{tabular}{|c|c|c|c|c|c|}
\hline \multicolumn{2}{|l|}{ Outcome measure } & \multirow{2}{*}{$\begin{array}{c}\text { Total } \mathbf{N}=\mathbf{2 4 2} \\
98(40.5 \%) \\
144(59.5 \%)\end{array}$} & \multirow{2}{*}{$\begin{array}{c}\text { Live } \mathbf{N}=\mathbf{1 6 2} \\
88(54.3 \%) \\
74(45.7 \%)\end{array}$} & \multirow{2}{*}{$\begin{array}{c}\text { Dead N = 80 } \\
56(70.0 \%) \\
24(30.0 \%)\end{array}$} & \multirow{2}{*}{$\frac{p \text { value }}{0.01}$} \\
\hline Sex $^{*}$ & $\begin{array}{l}\text { Male } \\
\text { Female }\end{array}$ & & & & \\
\hline Nutritional status ${ }^{*}$ & $\begin{array}{l}\text { Normal } \\
\text { Malnutrition }\end{array}$ & $\begin{array}{l}158(65.3 \%) \\
84(34.7 \%)\end{array}$ & $\begin{array}{c}110(67.9 \%) \\
52(32 \%)\end{array}$ & $\begin{array}{l}48(60 \%) \\
32(40 \%)\end{array}$ & 0.5 \\
\hline Blood diseases and cancer* & & $126(52 \%)$ & $88(54.3 \%)$ & $38(47.5 \%)$ & 0.6 \\
\hline Microorganism isolation (yes) & & $92(38.0 \%)$ & $61(137.6 \%)$ & $31(38.1 \%)$ & 0.5 \\
\hline PIM2 (score) ** & & $10(3-10)$ & $7 \pm 2$ & $11 \pm 2$ & 0.0001 \\
\hline $\mathbf{A K I}^{*}$ & $\begin{array}{l}\text { No risk } \\
\text { Risk } \\
\text { Injury } \\
\text { Failure }\end{array}$ & $\begin{array}{c}154(63.6 \%) \\
58(24.0 \%) \\
22(9.1 \%) \\
8(3.3 \%)\end{array}$ & $\begin{array}{c}98(60.5 \%) \\
44(27.2 \%) \\
14(8.6 \%) \\
6(3.7 \%)\end{array}$ & $\begin{array}{c}56(70 \%) \\
14(17.5 \%) \\
8(10 \%) \\
2(2.5 \%)\end{array}$ & 0.3 \\
\hline Type of septic shock* & $\begin{array}{l}\text { Hyperdynamic } \\
\text { Hypodynamic }\end{array}$ & $\begin{array}{l}166(68.6 \%) \\
76(31.4 \%)\end{array}$ & $\begin{array}{l}120(74.1 \%) \\
42(25.9 \%)\end{array}$ & $\begin{array}{l}46(57.5 \%) \\
34(42.5 \%)\end{array}$ & 0.007 \\
\hline Refractory shock (yes) ${ }^{*}$ & & $30(12.4 \%)$ & $12(7.14 \%)$ & $18(22.5 \%)$ & 0.001 \\
\hline Time (min) to antibiotic initia & $\operatorname{tion}^{* * *}$ & $45 \pm 2.3$ & $42 \pm 17$ & $61 \pm 18$ & 0.007 \\
\hline Mechanical ventilation* & $216(90 \%)$ & $136(83.9 \%)$ & $80(100 \%)$ & 0.05 & \\
\hline Hemoglobin $(\mathrm{g} / \mathrm{dL})^{* * *}$ & $9.5 \pm 3.1$ & $10.3 \pm 2$ & $9.4 \pm 1.5$ & 0.07 & \\
\hline Oncotic pressure $(\mathrm{mmHg})^{* * *}$ & $23 \pm 4$ & $24 \pm 1.2$ & $21 \pm 1.4$ & 0.01 & \\
\hline $\begin{array}{l}\text { Central venous } \\
\text { oxygen saturation }(\%)^{* * *}\end{array}$ & $73 \pm 8$ & $75 \pm 12$ & $66 \pm 14$ & 0.02 & \\
\hline $\begin{array}{l}\text { Days on amines/ } \\
\text { vasopressors }\end{array}$ & $2(0-4)$ & $1(0-3)$ & $2(1-4)$ & 0.5 & \\
\hline Serum lactate $(\mathrm{mmol} / \mathrm{L})^{* * *}$ & & $3.4 \pm 1.2$ & $3.2 \pm 1.7$ & $4.3 \pm 1.5$ & 0.04 \\
\hline$\%$ of fluid overload ${ }^{* * *}$ & $\begin{array}{l}24 \mathrm{~h} \\
48 \mathrm{~h} \\
72 \mathrm{~h} \\
96 \mathrm{~h}\end{array}$ & $\begin{array}{c}2.1(0.75) \\
3.3(0.89) \\
3.8(1.2) \\
4.4(2.3)\end{array}$ & $\begin{array}{l}4.5 \pm 1.2 \\
2.7 \pm 0.9 \\
2.1 \pm 1.1 \\
1.3 \pm 0.7\end{array}$ & $\begin{array}{c}8 \pm 3.4 \\
9 \pm 2.1 \\
11 \pm 4.2 \\
17 \pm 6.1\end{array}$ & $\begin{array}{c}0.2 \\
0.0001 \\
0.0001 \\
0.0001\end{array}$ \\
\hline
\end{tabular}

* Stated as frequency (percentage); the $\chi 2$ test was used.

** Stated as median (interquartile range); the Mann-Whitney U test was used.

*** Stated as mean (standard deviation); Student's t test was used.

AKI: acute kidney injury; PIM2: pediatric index of mortality.

TABLE 2. Comparison between live and dead patients due to septic shock and estimation of the hazard ratio according to the percentage of fluid overload in pediatric patients with septic shock

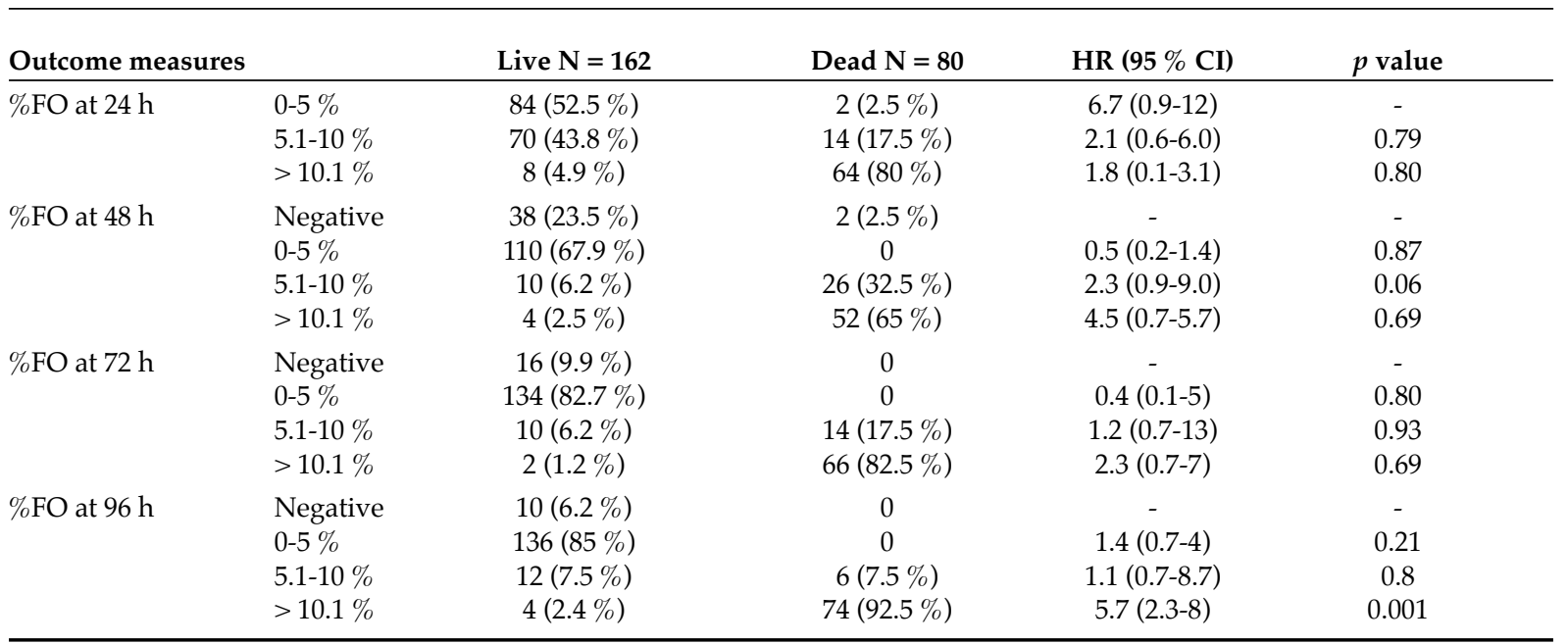

The dash (-) refers to the reference category.

HR: hazard ratio; CI: confidence interval; \%FO: percentage of fluid overload. 
For the first model, the baseline hemodynamic profile was considered (to avoid colinearity with the development of refractory shock). In the Cox proportional hazard analysis, it showed that a $\% \mathrm{FO} \geq 10.1 \%$, serum lactate, kidney injury, and time to antibiotic initiation were the most commonly associated outcome measures. A hyperdynamic profile was observed in $68.6 \%$ of patients. However, the proportion of deaths was higher among those with a hypodynamic

FIGURE 2. Comparison of the percentage of fluid overload accumulated per day between live and dead patients due to septic shock

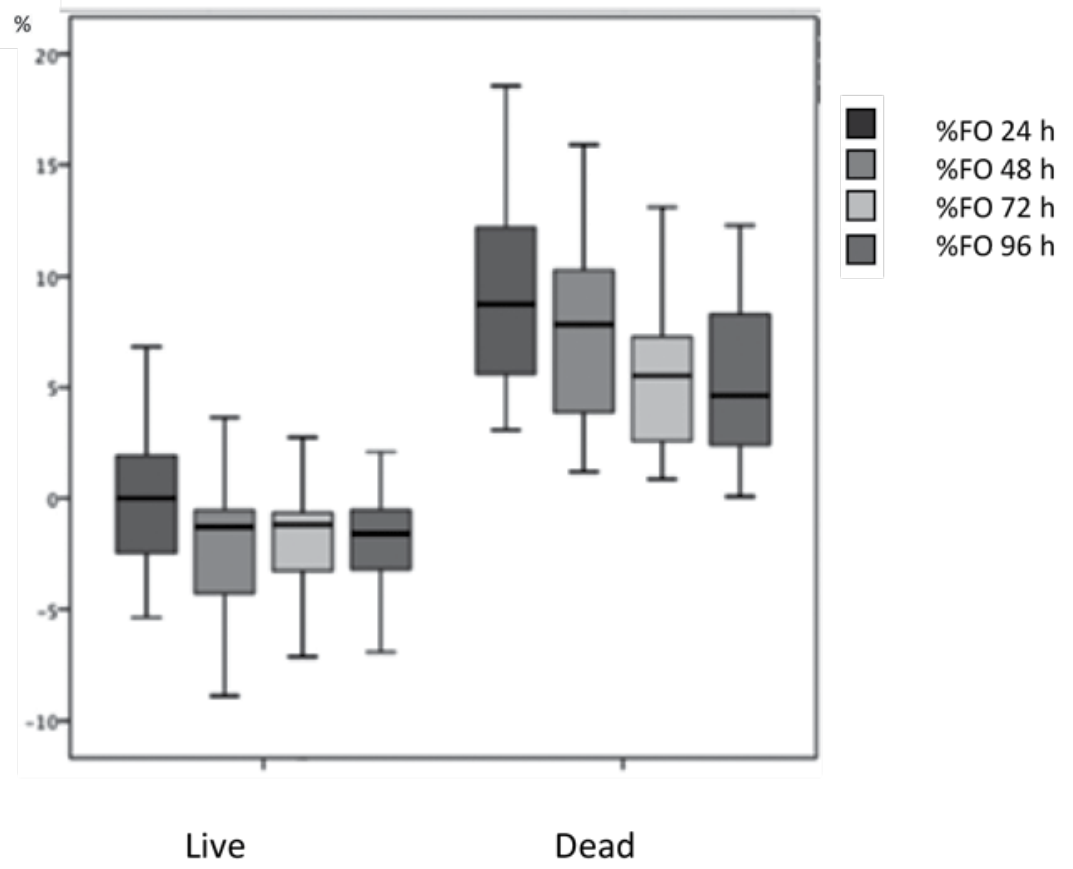

TABLE 3. Estimation of the hazard ratio for death among patients with septic shock

\begin{tabular}{|c|c|c|c|c|}
\hline Outcome measure & $\begin{array}{l}\text { Bivariate analysis } \\
\qquad \mathrm{N}=242 \\
\end{array}$ & $\begin{array}{c}\text { Model } 1 \\
\text { Hemodynamic profile } \\
\mathrm{N}=242 \\
\end{array}$ & $\begin{array}{c}\text { Model } 2 \\
\text { Refractory septic shock } \\
\mathrm{N}=242\end{array}$ & $\begin{array}{c}\text { Model } 3 \\
\text { Malnutrition } \\
\mathrm{N}=84\end{array}$ \\
\hline & Crude HR & Adjusted HR & Adjusted HR & Adjusted HR \\
\hline$\% \mathrm{FO}$ at $96 \mathrm{~h}>10.1 \%$ & $5.7(2.3-8)$ & $2.6(1.9-5.6)$ & $2.5(1.6-5.6)$ & $8.3(3.5-14)$ \\
\hline PIM2 (score) & $1.2(1.1-1.4)$ & $1.1(1.06-1.34)$ & $1.2(1.19-1.5)$ & $1.1(1.03-2)$ \\
\hline Microorganism isolation (yes) & $4.8(2.4-10)$ & $3.5(1.4-5.1)$ & $2.3(1.2-7)$ & NS \\
\hline AKI (injury / failure) & $2.3(1.2-4.1)$ & $3.7(1.8-7.6)$ & NS & $4.5(2.3-12)$ \\
\hline Lactate $>4 \mathrm{mmol} / \mathrm{L}$ & $1.6(1-2.5)$ & $2.03(1.23-3.34)$ & NS & NS \\
\hline Oncotic pressure $(\mathrm{mm} / \mathrm{Hg})$ & $1.5(1.2-2.5)$ & NS & NS & $1.4(1.2-3)$ \\
\hline Time (min) to antibiotic initiation & $1.1(1-1.3)$ & $1.1(1-1.4)$ & NS & NS \\
\hline Hypodynamic shock (yes) & $1.49(1.1-2.3)$ & NS & NS & NS \\
\hline Refractory shock (yes) & $1.9(1.3-3.2)$ & NI & $1.49(1.2-2.4)$ & NS \\
\hline
\end{tabular}

AKI: acute kidney injury; \%FO: percentage of fluid overload; HR: hazard ratio; PIM2: pediatric index of mortality; NI: not included in Cox proportional hazard analysis; NS: not significant.

Model 1: it included \%FO at 96 h, PIM2, AKI, microorganism isolation, lactate, oncotic pressure, resuscitation time, and type of shock.

Model 2: it included \%FO at 96 h, PIM2, AKI, microorganism isolation, lactate, oncotic pressure, resuscitation time, and refractory shock.

Model 3: in patients with malnutrition, it included \%FO at 96 h, PIM2, AKI, microorganism isolation, lactate, oncotic pressure, resuscitation time, type of shock, and refractory shock. 
phase in the first $24 \mathrm{~h}$, which is consistent with the publication by Ceneviva et al., ${ }^{8}$ who found that a hypodynamic profile was related to a lower survival.

The second model analyzed the presence of refractory shock and found that the only associated outcome measures were the \%FO accumulated at $96 \mathrm{~h}>10 \%$ and the PIM2 score. Authors like Weiss et al., ${ }^{26}$ have established that when septic shock is refractory to inotropes / vasopressors, mortality increases to $34 \%$. In this cohort, the frequency of refractory shock was $12.4 \%$, and was higher in the dead patient group $(22.5 \%$ versus $7.1 \%)$.

The third model adjusted the effect of malnutrition, which was observed in $34.6 \%$ and was higher in the dead patient group; such association was already reported in other studies conducted in Africa as a cause of death. ${ }^{27}$ Besides the $\% \mathrm{FO}$, other outcome measures of risk were oncotic pressure and kidney damage. This is explained as a result of the loss of oncotic and hydrostatic pressure (due to septic shock), which generates the leakage of administered fluids to the interstitial space and results in kidney injury due to prerenal failure mechanism.

In children, the association between kidney failure and septic shock is expected to be $30 \%$ with an increased likelihood of death. ${ }^{28}$ In this cohort, the frequency of injury/failure was $36.4 \%$, and was maintained in two of the prognostic models. In this regard, Na Wang et al. documented, in a multicenter study conducted in adults (2526 patients), an increase in mortality in the presence of fluid overload and acute kidney injury. ${ }^{29}$

In our study, the outcome measure corresponding to antibiotic initiation accounted for a $\mathrm{HR}=1.1$ (1-1.4) for every minute lapsed as of the diagnosis of shock. In this regard, Morneau et al., identified, in adult patients with cancer, a $16 \%$ increase in hypotension for every hour of delay. ${ }^{30}$

In other similar studies, the validated pediatric mortality scales at the PICU, regardless of the scale, were permanently included in the prognostic models. ${ }^{19,21-23}$ For our cohort, we selected the PIM2 score, which remained independent in all final prognostic models, which added consistency to the reported evidence and allowed to ponder over the predictive ability of $\% \mathrm{FO}$.

The main strength of this study is the analysis of the predictive ability of $\% \mathrm{FO}$ over other outcome measures, such as malnutrition, febrile neutropenia, and the hemodynamic profile of septic shock, using different prognostic models.

A weakness of the method that is worth noting is the inclusion of a single site, which may affect

FIGURE 3. Survival curve for patients with septic shock categorized by percentage of fluid overload accumulated at 96 hours

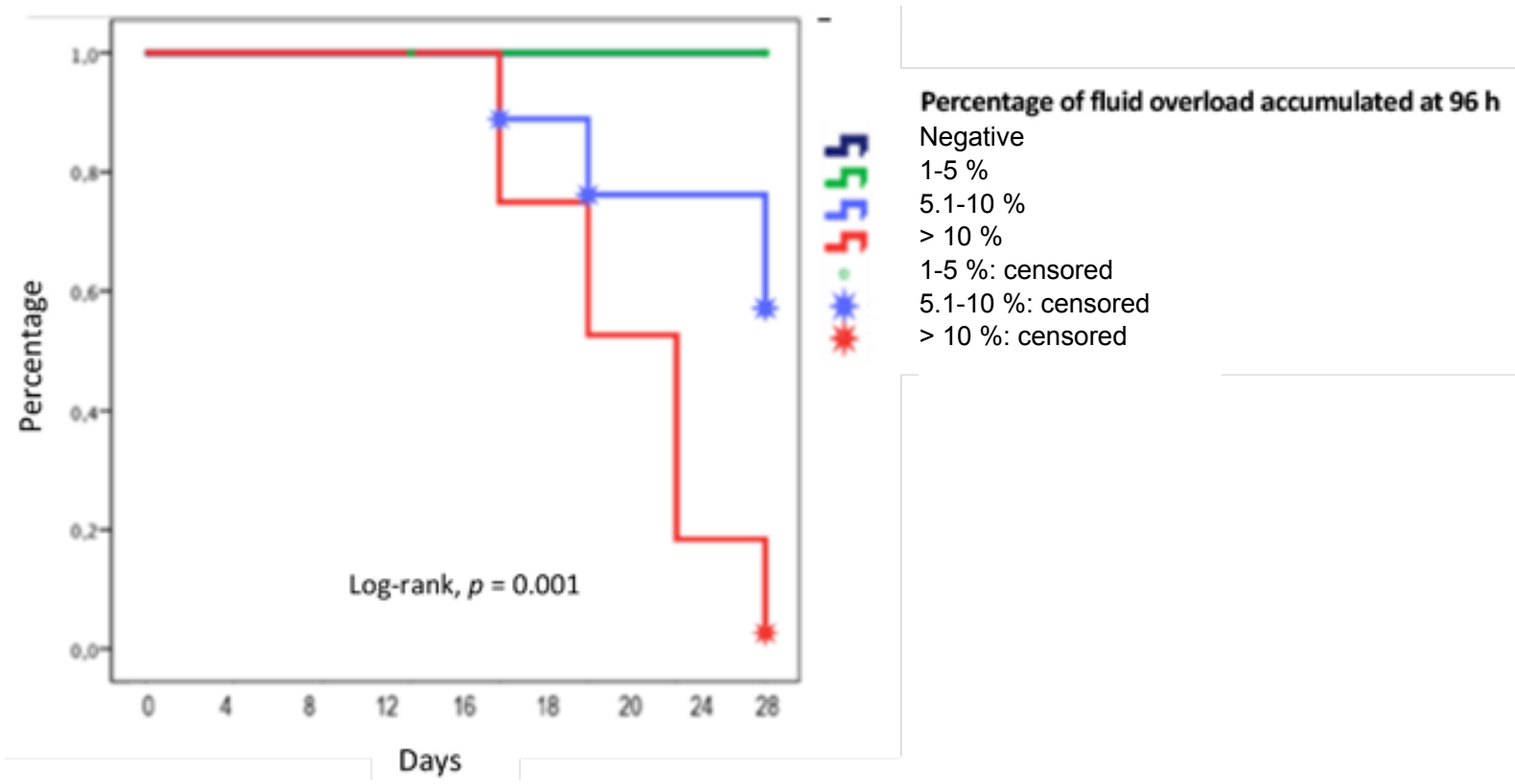

The probability of being alive at 28 days with a $\% \mathrm{FO}$ of $0-5 \%$ is $100 \% ; 5.1-10 \%, 58 \% ; \% \mathrm{FO}<10.01 \%, 2 \%$. 
the results' external validity because it is not possible to rule out a selection bias (due to the type of patients) or poor classification, as in the assessment of the hemodynamic profile, due to the use of gold standard surrogates.

It is worth conducting a multicenter study that allows to adjust the effect of other outcome measures, such as the type of antibiotic therapy, surgical management, presence of congenital heart disease, and other chemical outcome measures.

\section{CONCLUSION}

In patients with septic shock, a $\% \mathrm{FO} \geq 10.1 \%$ was related to a higher mortality at 28 days of adjustment to the hemodynamic profile, refractory shock, and nutritional status.

\section{REFERENCES}

1. Ruth A, McCracken CE, Fortenberry JD, Hall M, et al. Pediatric severe sepsis: current trends and outcomes from the Pediatric Health Information Systems database. Pediatr Crit Care Med. 2014; 15(9):828-38.

2. Sakr Y, Rubatto Birri PN, Kotfis K, Nanchal R, et al. Higher Fluid Balance Increases the Risk of Death From Sepsis: Results From a Large International Audit. Crit Care Med. 2017; 45(3):386-94.

3. Woodcock TE, Woodcock TM. Revised Starling equation and the glycocalyx model of transvascular fluid exchange: an improved paradigm for prescribing intravenous fluid therapy. Br J Anaesth. 2012; 108(3):384-94.

4. Hoste EA, Maitland K, Brudney CS, eMahta R, t al. Four phases of intravenous fluid therapy: a conceptual model. Br J Anaesth. 2014; 113(5):740-7.

5. Glassford NJ, Bellomo R. The Complexities of Intravenous Fluid Research: Questions of Scale, Volume, and Accumulation. Korean J Crit Care Med. 2016; 31(4):276-99.

6. Workman JK, Ames SG, Reeder RW, Korgenski EK, et al. Treatment of Pediatric Septic Shock With the Surviving Sepsis Campaign Guidelines and PICU Patient Outcomes. Pediatr Crit Care Med. 2016; 17(10):e451-8.

7. National High Blood Pressure Education Program Working Group on High Blood Pressure in Children and Adolescents. The fourth report on the diagnosis, evaluation, and treatment of high blood pressure in children and adolescents. Pediatrics. 2004; 114(2Suppl $4^{\text {th }}$ Report):555-76.

8. Ceneviva G, Paschall JA, Maffei F, Carcillo JA. Hemodynamic support in fluid-refractory pediatric septic shock. Pediatrics. 1998; 102(2):e19.

9. Keeley A, Hine $\mathrm{P}, \mathrm{N}$ sutebu $\mathrm{E}$. The recognition and management of sepsis and septic shock: a guide for nonintensivists. Postgrad Med J. 2017; 93(1104):626-34.

10. Hartman ME, Saeed MJ, Powell KN, Olsen MA. The Comparative Epidemiology of Pediatric Severe Sepsis. J Intensive Care Med. 2017:885066617735783.

11. Mesquida J, Saludes P, Gruartmoner G, Espinal C, et al. Central venous-to-arterial carbon dioxide difference combined with arterial-to-venous oxygen content difference is associated with lactate evolution in the hemodynamic resuscitation process in early septic shock. Crit Care. 2015; 19:126.
12. Schantz DI, Chen RP. A practical method of measuring oxygen consumption in children with complex mixing circulations by the use of thermodilution cardiac output studies. J Thorac Cardiovasc Surg. 2013; 146(5):1179-84.

13. Williams FZ, Sachdeva R, Travers CD, Walson KH, et al. Characterization of Myocardial Dysfunction in Fluid- and Catecholamine-Refractory Pediatric Septic Shock and Its Clinical Significance. I Intensive Care Med. 2016:885066616685247.

14. Sutherland SM, Zappitelli M, Alexander SR, Chua AN, et al. Fluid overload and mortality in children receiving continuous renal replacement therapy: the prospective pediatric continuous renal replacement therapy registry. Am J Kidney Dis. 2010; 55(2):316-25.

15. Straney L, Clements A, Parslow RC, Pearson G, et al. Paediatric index of mortality 3: an updated model for predicting mortality in pediatric intensive care. Pediatr Crit Care Med. 2013; 14(7):673-81.

16. Selby NM, Lennon R. Be on alert for pediatric AKI. Kidney Int. 2017; 92(2):286-8.

17. Waterlow JC. Classification and definition of protein-calorie malnutrition. Br Med J. 1972; 3(5826):566-9.

18. Vázquez-Rodríguez J. Presión coloidosmótica plasmática, índice de Briones y ascitis en preeclampsia-eclampsia. Cir Cir. 2010; 78(2):137-43.

19. Chen J, Li X, Bai Z, Fang F, et al. Association of Fluid Accumulation with Clinical Outcomes in Critically Ill Children with Severe Sepsis. PLoS One. 2016;11(7):e0160093.

20. Garzotto F, Ostermann M, Martin-Langerwerf D, Sánchez-Sánchez M, et al. The Dose Response Multicentre Investigation on Fluid Assessment(DoReMIFA) in critically ill patients. Crit Care. 2016; 20(1):196.

21. Abulebda K, Cvijanovich NZ, Thomas NJ, Allen GL, et al. Post-ICU admission fluid balance and pediatric septic shock outcomes: a risk-stratified analysis. Crit Care Med. 2014; 42(2):397-403.

22. Willson DF, Thomas NJ, Tamburro R, Truemper E, et al. The relationship of fluid administration to outcome in the pediatric calfactant in acute respiratory distress syndrome trial. Pediat Crit Care Med. 2013; 14(7):666-72.

23. Bhaskar P, Dhar AV, Thompson M, Quigley R, et al. Early fluid accumulation in children with shock and ICU mortality: a matched case-control study. Intensive Care Med. 2015; 41(8):1445-53.

24. Alkhodair A, Tsang MYC, Cairns JA, Swiston JR, et al. Comparison of thermodilution and indirect Fick cardiac outputs in pulmonary hypertension. Int J Cardiol. 2018; 1258:228-31.

25. Chew MS, Poelaert J. Accuracy and repeatability of pediatric cardiac output measurement using Doppler: 20-year review of the literature. Intensive Care Med. 2003; 29(11):1889-94.

26. Weiss SL, Balamuth F, Hensley J, Fitzgerald JC, et al. The Epidemiology of HospitalDeath Following Pediatric Severe Sepsis: When, Why, and How Children With Sepsis Die. Pediatr Crit Care Med. 2017; 18(9):823-30.

27. Kambale RM, Kasengi JB, Kivukuto JM, Cubaka LM, et al. Profil infectieux et mortalité des enfants âgés de 0 à 5 ans admis pour malnutrition aiguë sévère: étude de cohorte rétrospective au Centre Nutritionnel et Thérapeutique de Bukavu, République Démocratique du Congo.Pan Afr Med J. 2016; 23:139.

28. Duzova A, Bakkaloglu A, Kalyoncu M, Poyrazoglu H, et al. Etiology and outcome of acute kidney injury in children. Pediatr Nephrol. 2010; 25(8):1453-61.

29. Wang N, Jiang L, Zhu B, Wen Y, et al. Fluid balance and mortality in critically ill patients with acute kidney injury: a multicenter prospective epidemiological study. Crit Care. 2015; 19:371.

30. Morneau K, Chisholm GB, Tverdek F, Bruno J, et al. Timing to antibiotic therapy in septic oncologic patients presenting without hypotension. Support Care Cancer. 2017; 25(11):3357-63 